\title{
School Adjustment, Locus of Control and Achievement Motivation as Predictor of Test Anxiety
}

\section{Ogbogo Stella, Amaechi-Udogu Vivian Chukwunonyenim}

\author{
Department of Educational Psychology, G/C, Faculty of Education, University of Port Harcourt, Rivers \\ State, Nigeria \\ Department of Educational Psychology, G/C, Faculty of Education, University of Port Harcourt, Rivers \\ State, Nigeria
}

\begin{abstract}
The study investigated school adjustment, locus of control and achievement motivation as predictor of test anxiety amongst secondary school students in obio-Akpor LGA in Rivers State Nigeria. Five research questions and four null hypotheses were formulated to guide the study Multiple prediction design within the correlational research design was employed for the study, the population of the study was 10,705 junior secondary school students (JSS1) in 14 school in Obio-Akpor Local Government Area Of Rivers state. Stratified sampling technique based on gender was used to obtain the sample size of 388 (male 190 and female 198). Four valid instrument titled; Test Anxiety Questionnaire (TAQ), Locus of Control Questionnaire (LOCQ), School Adjustment Questionnaire (SAQ) and Achievement Motivation Questionnaire (AMQ). The reliability and construct validity of these instruments were estimated using the internal consistency method of Cronbach alpha. For Test Anxiety Questionnaire, Cronbach Alpha reliability coefficient was .846, for Locus of Control Questionnaire it was .618, for Achievement Motivation Questionnaire, it was .545 and for School Adjustment it was .611. Research question 1, was answered using descriptive statistics of mean and standard deviation, while 2, 3, 4 and 5 was answered using simple and multiple regression. At 0.05 level of significance, ANOVA associated with multiple regression and $t$ - test associated with simple regression was used for testing the null hypothesis. The result revealed that test anxiety of secondary school students was high, school adjustment and achievement motivation predict test anxiety significantly with locus of control predicting test anxiety but not significantly. Jointly, school adjustment, locus of control and achievement motivation predicted test anxiety significantly. Based on findings recommendations were made.
\end{abstract}

\section{Introduction}

The essence of learning or education is that there is performance change in behavior and this performance change is ascertained usually via the administration of a test. Test or examination results play a significant role in the Milieu of high stakes decision-making, which includes, admission aptitude achievement and certification, employment opportunities, higher incomes and so on. Thus once significance is attached to a person's test score, the individual will experience some repercussions, ranging from superficial to life changing. Thus students are most times under pressure to achieve academically and are seen to most times worry and have fear during test. A situation which is known as'test anxiety'. Test anxiety is a psychological condition in which people experience extreme distress, discomfort, and anxiety in testing situations ( Zeidner, 1998). It is a feeling of worry, apprehension, nervousness or uneasiness that occurs when a student encounters test or examination in any form and at any level (Onyeizugbo, 2010). Test anxiety involves four main components; cognitive, emotionality, behavioral, and physical components (Zeidner, 1998). The cognitive component is the mental activity that revolves around the testing situation. It constitutes elements such as thinking about consequences of failure, racing thoughts, negative and worrisome thoughts, problem in recalling facts, difficulty in reading and understanding questions etc. The emotionality component is characterized by tension, fear, apprehension, and nervousness towards test or examinations, which is usually associated with 
somatic symptoms such as palpitation, nausea, perspiration, headaches, stomach aches, nausea, diarrhea, excessive sweating, rapid heartbeat, dry mouth, and shortness of breath. The behavioral component involves fidgeting, feeling of restlessness etc., while the physical component is characterized by poor study skills, avoidance and procrastination of work and physical discomfort (Onyeizugbo, 2010).

Minimal or moderate amount of anxiety helps the body to carry out some task better thus, some sort of degree of test anxiety is needed by students to succeed in academic endeavor, however, test anxiety has debilitating effect, when it increases beyond optimal level. When students experience high levels of test anxiety, they tend to experience negative physiological reactions such as increase heartbeat, excessive sweating, dizziness, headaches, high blood pressure, and nausea, fidgeting, fear, tension, excessive worry, feeling of wanting to cry, hopelessness, and restlessness amongst other. All these might make it difficult for them to prepare well, comprehend relatively simple instructions, organize or recall relevant information, concentrate, and perform adequately during tests (Onyeizugbo, 2010; Zeidner, 1998). Bernstein et al (2006) postulated that too much arousal, or even too little, tends to result in decreased performance.

Test anxiety is quite prevalent and widespread and studies have shown that an estimate of 2-3 students in any given classroom are highly anxious due to test anxiety, and that test anxiety can surface as early as age seven, and It is estimated that from $10 \%$ to $46 \%$ of school students experience test anxiety during tests and examinations, and that male and female students suffer from the problem equally (Bernstein Penner, Clerk-Stewart \& Roy 2006; Cassady, 2010;, Ergene, 2003: 2013).

Test Anxiety generally does not develop in a vacuum. Many factors contribute to the development of test anxiety, some of which are fear of failing, consistently thinking about consequences of failure, procrastination, poor study habit, inadequate of knowledge of course materials, school adjustment, locus of control, consistent poor performance, past experiences and beliefs, lack of confidence in one's ability, characteristics of the test environment; such as the nature of the test, time constraints, examiner characteristics, mode of test administration and physical setting achievement motivation ( Putwain, Woods, \& Symes, 2010; Sujit \& Kavita, 2006).

School adjustment plays a vital role in a child's life, and it is like a pillar on which child's entire life is based (Lakhan, Jain \& Chande 2017) viewed. They saw school adjustment is the process of adapting to the role of being a student and to various aspects of the school environment. School adjustment is the process of adapting or finding one's mode of behavior appropriate to a school environment. Feeling comfortable, manifestation of great interest in academic pursuit, relaxed, happy, and positive attitude about school and learning are signs that may show that an individual is well adjusted to school. An individual is not born adjusted; it is his or her capabilities that make him negotiate possible challenges to get adjusted in any environment and negotiate possible challenges that might prevent adjustment. ( Lakhan et al 2017). Success in negotiating these challenges predicts school success especially as regards testing. This thus is important to understand the role of school adjustment in predicting test anxiety. An individual is not born adjusted; it is his or her capabilities that make his or her adjusted in any environment. (Lakhan et al 2017). Adjustment to school is influenced by a variety of the child's personal characteristics and their experiences, family characteristic and societal trend and. Student who are not well adjusted to school may experience anxieties in school related activities including test

One factor that may contribute to test anxiety also is locus of control. Locus of control was developed by Jullian Rotter in 1996 to measure the location of control of the individual. The construct, locus of control is a theory that accounts for how people perceive and explain successes and failures in their live.

Locus of control is usually in two dimensions, internal and external locus of control. Internal locus of control is when success or failure is attributed ability and effort while external locus of control attributes success or failure to task difficulty and luck. An individual who has internal locus of control for instance, is one who makes his own feelings and decisions and is in control of his actions and behaviors. On the other hand, an individual with external locus of control sees others, circumstances or luck beyond his control as being responsible for his actions

Another factor that may contribute to test anxiety mentioned in literature is achievement motivation. The concept achievement motivation is a type of motivation which refers to the need for success or attainment of excellence. It is "competition with a standard of excellence."( Chuan 2016. Mondal et al., (2013), defined achievement motivation as the need for success or the attainment 
of excellence. According to Bernstein et al, (2006) achievement motivation tends to be learned in early childhood. Onukwofor \& Ugwu (2017) opined that individuals who have the trait of achievement motivation tend to put in every possible effort to achieve success both in academic and other fields of human endeavor. In the same light, Mondal et al (2013) and Erdoğan, Kesici, \& Sahin (2011)asserted that individuals with high achievement motivation may experience low level of anxiety because they have high self-confidence, are highly focused, calm, bold, and have high determination to surpass high standards of excellence in competitive task. Although, Balogun, Balogun \& Onyeacho (2017) viewed that, achievement motivation may also increase students' level of test anxiety as high achievement expectations may lead to high performance standards which may consequently culminate in high levels of anxiety in face of evaluation

In recent times, to combat the issues of anxieties facing students, a lot of research has been carried out in the area of test anxiety. For instance, study by Onyekwuru \& igbelam (2014), $18.13 \%$ of the students had high test anxiety. This is similar to the findings of Rezazadeh and Tavakoli (2009) who found that $11.8 \%$ of the students had high test anxiety. Furthermore, Khan, Haider, Ahmed, and Khan (2011) in a study, reported a negative relationship between achievement motivation and anxiety. Similarly, in 2015, Khalaila found that nursing students with high intrinsic motivation experienced low level of test anxiety. Likewise Onukwofor \& Ugwu in (2017) who found out in their study that self-concept, test anxiety and achievement motivation jointly significantly predicted academic achievement. In the same vein, in 2017, Balogun et al, study showed that test anxiety had a negative impact on academic performance and achievement motivation significantly moderated the relationship between test anxiety and academic performance. Also a study by Alam \& Halder (2018) revealed a statistical significant negative correlation between test anxiety and adjustment

As earlier mentioned, it has been suggested in literature that test anxiety do not operate in a vacuum and has factors contributing to it. However, variables like achievement motivation, locus of control and adjustment to school has received little or no empirical attention and has not been given adequate empirical attention on their prediction on test anxiety. Precisely, conducting the study amongst students in Nigeria is warranted, because studies ( Bernsteinm et al 2006; Cassady, 2010; Ergene, 2003:Onyekwuru \& igbelam 2014 ; Rezazadeh and Tavakoli 2009) have shown that the issue of test anxiety is becoming more prevalent among student. The extent to which a child is adjusted to school goes a long way in determining the level of a child's anxiousness concerning activities in the school especially in area of testing which gives an index of a student's achievement in school that in turns determine how the students sees self and also the society. The direction where a student attributes his success or failure to, may determine the level of anxiousness he or she brings to the testing situation. Also achievement motivation which is the need for success or excellence may drive a student to obtain dominance in challenging and difficult test anxiety related issues. The issue of test anxiety is becoming more prevalent and the effect worrisome as when students' are test anxious, performance is compromised and performance in school may connect with their performance in real life i.e., outside school.

These are thus valid and important research concerns and in response, calls for more empirical studies, thus the primary aim of the present study which was to examined the prediction of school adjustment, locus of control achievement motivation on test anxiety. In guiding this study the following questions were asked and hypotheses formulated Research Question

1. What is the test anxiety level of secondary school students

2. To what extent does adjustment to school predict test anxiety

3. To what extent does locus of control predict test anxiety

4. To what extent does achievement motivation predict test anxiety

5. To what extent does adjustment to school, locus of control and achievement motivation, jointly predict test anxiety

Hypothesis

1. Adjustment to school does not significantly predict test anxiety

2. Locus of control does not significantly predict test anxiety

3. Achievement motivation does not significantly predict test anxiety

4. Adjustment to school, locus of control and achievement motivation, jointly does not significantly predict test anxiety

\section{Methodology}


This study employed the multiple prediction design within the correlational research design; Correlational design is used in a situation where the researcher seeks to establish the relationship between two or more variables. The population for the study was 10,705 junior secondary school students (JSS1) in 14 school in Obio-Akpor Local Government Area of Rivers state. Simple random sampling technique via balloting method was used to obtain 6 schools from the 14 schools. Stratified sampling technique based on gender was then used to obtain the sample size of 388 (male 190 and female 198). Four instruments Test Anxiety Questionnaire (TAQ), Locus of Control Questionnaire (LOCQ), Adjustment to School Questionnaire (ASQ) and Achievement Motivation Questionnaire (AMQ) was used for the study. The Achievement Motivation Questionnaire which is a 13 item was adapted from the Thomas and Muthee (2009) Achievement Motivation Inventory (AMS).The Test anxiety Questionnaire (TAQ) which is self-developed instrument consists of 16 items. The third instrument Locus of Control Questionnaire (LCQ) is self-developed consisting of 13 items while the fourth instrument Adjustment to School Scale (ASQ) is self-developed by the researcher. The instruments were all structured in the modified Likert Scale. The reliability and construct validity of these instruments were estimated using Cronbach alpha method of internal consistency. These instruments were pilot tested on a sample of 30 respondents. In line with Cronbach alpha method, every item in the instrument was analyzed for quality and selection. Item inclusion for the final instrument were based on the inter item analysis and item total statistics. Items which were considered inadequate were removed based on their weak position on coefficient compared to other items in the pool a system which ensured construct validity of the items in the instruments. For Test Anxiety Questionnaire, Cronbach Alpha reliability was .846, for Locus of Control Subscale, Cronbach Alpha reliability was .618, for Adjustment to School Subscale, Cronbach Alpha reliability was .611, for Achievement Motivation Subscale, Cronbach Alpha reliability was .545 , from the above, there were clear and adequate evidence that the scales had good psychometric properties of validity and reliability. The data collection was analyzed using mean and $\mathrm{SD}$ to answer research question 1, while research question 2-5 and hypothesis 1-3 were tested using ttest associated with simple regression, while ANOVA associated with multiple regression was used in answering research question 4 and testing hypothesis 4 at 0.05 significant level.

\section{Result}

Research Question 1: What is the test anxiety level of Secondary students?

Table 1.1: Mean and standard deviation analysis showing the test anxiety level of secondary school students

\begin{tabular}{|c|c|c|c|c|c|c|c|}
\hline & N & $\begin{array}{c}\text { M.nista } \\
\text { t }\end{array}$ & $\begin{array}{c}\text { Max } \\
\text {.Sta }\end{array}$ & $\begin{array}{c}\text { Sum } \\
\text { Sta }\end{array}$ & Mean & $\begin{array}{c}\text { Std. } \\
\text { Error }\end{array}$ & S D \\
\hline T. & 38 & 18 & 69 & $\begin{array}{c}16831 . \\
0\end{array}$ & $\begin{array}{c}43.26 \\
7\end{array}$ & $\begin{array}{c}.3522 \\
9\end{array}$ & $\begin{array}{c}6.94 \\
8\end{array}$ \\
\hline & 9 & & & & & & \\
\hline & & & & & & \\
\hline
\end{tabular}

The table 1.1 shows the mean score of 43.267 and standard deviation of 6.948 this implies that the test anxiety level of secondary school student is high. This is based on the fact that the mean of 43.26 is above the criterion mean point mean of 32.00

Research Question 2: To what extent does school adjustment predicts test anxiety?

Hypothesis 1: Adjustment to school does not significantly predict test anxiety.

Table 1.2: Showing regression analysis of the prediction of adjustment to school on test anxiety.

\begin{tabular}{|l|l|l|l|l|}
\hline Model & $\mathrm{R}$ & $\begin{array}{l}\mathrm{R} \\
\text { square }\end{array}$ & $\begin{array}{l}\text { Adjusted } \\
\mathrm{R}^{2}\end{array}$ & $\begin{array}{l}\text { Std. Err of } \\
\text { estimate }\end{array}$ \\
\hline 1 & .251 & .063 & 0.60 & 6.7432 \\
\hline
\end{tabular}

Table 1.2: This table shows the Regression coefficient $\mathrm{R}=.251, \mathrm{R}$ square $=.063$, adjusted $\mathrm{R}$ square $=.060$ and std. Error is seen to be 6.7432 . This shows that $\mathrm{R}$ is .251 which indicates a positive relationship between school adjustment and test anxiety that is school adjustment predicts test anxiety. The coefficient of determination $R^{2}, R$ square is .063 showing that the proportion of variance in test anxiety can be explained by school adjustment. This implies that $6 \%$ of the variation in test anxiety can be accounted for by school adjustment.

Table 1:3 t - test associated with simple regression showing the prediction of school adjustment on test anxiety.

\begin{tabular}{|l|c|c|c|c|c|}
\hline Model & \multicolumn{1}{|c|}{$\begin{array}{c}\text { Unstandard } \\
\text { ized } \\
\text { Coefficient }\end{array}$} & $\begin{array}{c}\text { Stan } \\
\text { dard } \\
\text { ized }\end{array}$ & T & Sig. \\
& \multicolumn{2}{|c|}{$\mathrm{s}$} & $\begin{array}{c}\text { Coef } \\
\text { ficie } \\
\text { nts }\end{array}$ & & \\
& \multicolumn{2}{|c|}{} & & \\
& & & & \\
& B & Std. & Beta & & \\
\hline
\end{tabular}




\begin{tabular}{|l|r|r|r|r|r|r|}
\hline \multicolumn{2}{|c|}{} & \multicolumn{9}{|c|}{$\begin{array}{c}\text { Err } \\
\text { or }\end{array}$} & & & \\
\hline (Consta & 34.7 & $\begin{array}{r}1.6 \\
99\end{array}$ & & 20.48 & .000 \\
nt) & 98 & 99 & 6 & \\
\hline School & .276 &. & .251 & 5.088 & .000 \\
adjustmt & & 0.5 & & & \\
& & 4 & & & \\
\hline
\end{tabular}

Table 1.3: the table shows Beta value $=.251$ and $t=$ $5.088(\mathrm{~B}=.251, \mathrm{t}=5.008 ; \mathrm{P}<0.05)$. The null hypothesis is rejected and this shows that is school adjustment significantly predicts test anxiety.

Research Question 2: To what extent does locus of control predicts test anxiety?

Hypothesis 1: Locus of control does not

Table 1.3: Showing regression analysis of the prediction of locus of control on test anxiety.

\begin{tabular}{|l|l|l|l|l|}
\hline Model & $\mathrm{R}$ & $\begin{array}{l}\mathrm{R} \\
\text { square }\end{array}$ & $\begin{array}{l}\text { Adjusted } \\
\mathrm{R}^{2}\end{array}$ & $\begin{array}{l}\text { Std. Err of } \\
\text { est. }\end{array}$ \\
\hline 1 & .030 & .001 & .002 & 6.9542 \\
\hline
\end{tabular}
positive relationship between locus of control and test anxiety that is locus of control predicts test anxiety. The coefficient of determination $\mathrm{R}^{2}, \mathrm{R}$ square is .001 showing that the proportion of variance in test anxiety that can be explained by locus of control. This implies that $1 \%$ only of the locus of control.

Table 1:4 t - test associated with simple regression showing the prediction of locus of control on test anxiety.

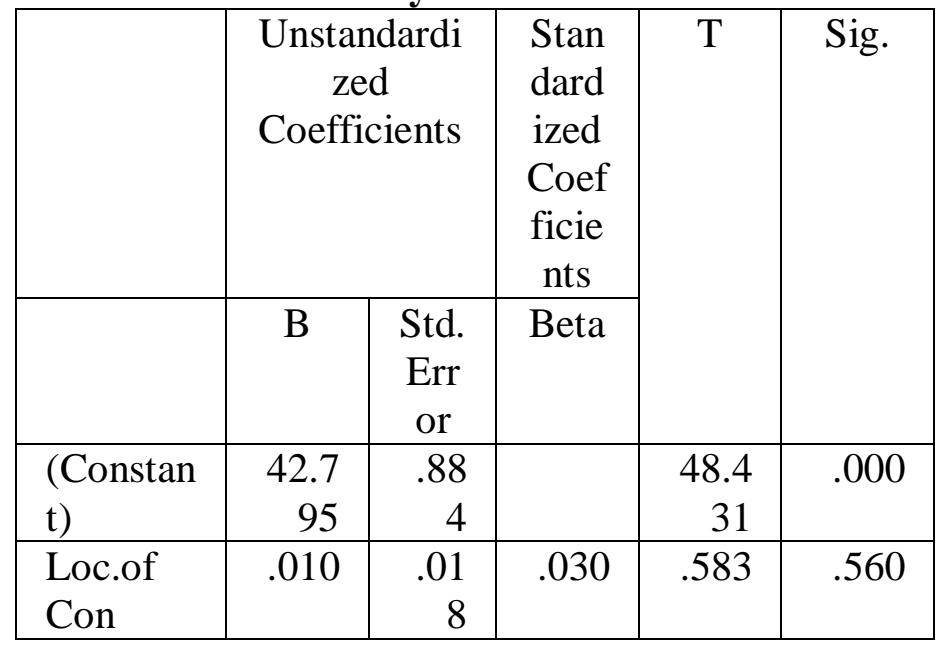

Table 1.4: the table shows Beta value $=.030$ and $\mathrm{t}=$ $.583(\mathrm{~B}=030, \mathrm{t}=.583 ; \mathrm{P}>0.05)$. The null hypothesis is accepted and this shows that locus of control significantly does not predicts test anxiety Research Question 4: To what extent does achievement motivation predicts test anxiety? significantly predict test anxiety.

Table 1.3: Shows that $\mathrm{R}$ is .030 which indicates a variation in test anxiety can be accounted for by

Hypothesis 3: Achievement motivation does not significantly predict test anxiety.

Table 1.5: Showing regression analysis of the prediction of Achievement Motivation on test anxiety.

\begin{tabular}{|l|l|l|l|l|}
\hline Model & $\mathrm{R}$ & $\begin{array}{l}\mathrm{R} \\
\text { square }\end{array}$ & $\begin{array}{l}\text { Adjusted } \\
\mathrm{R}^{2}\end{array}$ & $\begin{array}{l}\text { Std. Err of } \\
\text { est. }\end{array}$ \\
\hline 1 & .192 & .037 & .034 & 6.8282 \\
\hline
\end{tabular}

Table 1.5: Shows that $\mathrm{R}$ is .192 which indicates a positive relationship between achievement motivation and test anxiety that is achievement motivation predicts test anxiety. The coefficient of determination $\mathrm{R}^{2}$, $\mathrm{R}$ square is .037 showing that the proportion of variance in test anxiety that can be explained by achievement motivation. This implies that $3 \%$ of the variation in test anxiety can be accounted for by achievement motivation.

Table 1:6 t - test associated with simple regression showing the prediction of achievement motivation on test anxiety.

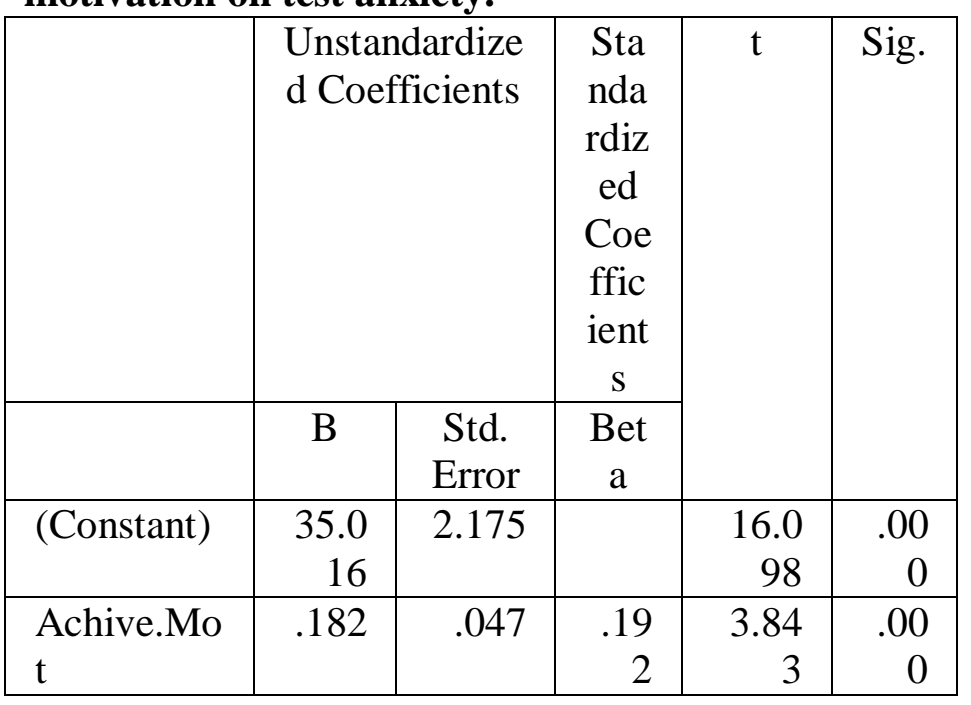

Table 1.6: the table shows Beta value $=.192$ and $\mathrm{t}=$ $3.843(\mathrm{~B}=030, \mathrm{t}=.583 ; \mathrm{P}<0.05)$. The null hypothesis is accepted and this shows that achievement motivation significantly does not predicts test anxiety

Research Question 5: To what extent does School Adjustment, Locus of control and achievement motivation jointly predict test anxiety?

Hypothesis 4: School Adjustment, Locus of control and achievement motivation jointly does not significantly predict test anxiety.

Table 1.7: Showing regression analysis of the joint prediction of School Adjustment, Locus of control and Achievement Motivation on test anxiety.

\begin{tabular}{|l|l|l|l|l|}
\hline Model & $\mathrm{R}$ & $\begin{array}{l}\mathrm{R} \\
\text { square }\end{array}$ & $\begin{array}{l}\text { Adjusted } \\
\mathrm{R}^{2}\end{array}$ & $\begin{array}{l}\text { Std. Err of } \\
\text { est. }\end{array}$ \\
\hline 1 & .304 & .092 & .085 & 6.6531 \\
\hline
\end{tabular}


Table 1.7: Shows that $\mathrm{R}$ is .304 which indicates a positive relationship between School Adjustment, Locus of control, Achievement Motivation and test anxiety that is School Adjustment, Locus of control, Achievement Motivation jointly predicts test anxiety. The coefficient of determination $\mathrm{R}^{2}, \mathrm{R}$ square is .092 showing that the proportion of variance in test anxiety that can be explained jointly by School Adjustment, Locus of control and Achievement Motivation. This implies that 9\% of the variation in test anxiety can be accounted for jointly by School Adjustment, Locus of control and Achievement Motivation.

Table 1.8: ANOVA associated with multiple regression showing the joint prediction of School Adjustment, Locus of control and Achievement Motivation on test anxiety

\begin{tabular}{|l|l|l|l|l|l|}
\hline Model & $\begin{array}{l}\text { Sum of } \\
\text { square }\end{array}$ & Df & $\begin{array}{l}\text { Mean } \\
\text { square }\end{array}$ & F & Sig \\
\hline Regression & 1731.712 & 3 & 577.237 & 13.041 & 000 \\
\hline Residual & 16997.474 & 384 & 44.264 & & \\
\hline Total & 18729.186 & 387 & & & \\
\hline
\end{tabular}

Table 1.8: Shows an F - value of $13.041 \mathrm{df}$ $=(384) \mathrm{P}<.05$. The null hypothesis thus of School Adjustment, Locus of control and achievement motivation jointly not significantly predicting test anxiety is rejected. This implies School Adjustment, Locus of control and achievement motivation jointly significantly predicts test anxiety

\section{Discussion and Conclusion}

This study focused on the prediction of School Adjustment, Locus of control and achievement motivation on test anxiety. The findings of this study reveals that the test anxiety of graduate students is high as the mean score of 43.00 is high and above the criterion mean. This is consistent with the findings of ; Cassady, 2010, , Bernstein et al 2006, Onyekwuru \& Ibegbunam 2014 and Rezazadeh \& Tavakoli 2009 where it is estimated that from $10 \%$ to $46 \%$ of school students experience test anxiety during tests and examinations. This result shows that students experience feeling of panic, worry, nauseous and other anxiety related behaviors during, before and after test

The finding of the present study shows that adjustment to school significantly predicts statistics anxiety from table 1:2 and 1:3 where $\mathrm{P}<.05$ when data was analyzed using simple regression. Coefficient of determination shows that only $6 \%$ of the variation in the proportion of school adjustment can be accounted for by the prediction of school adjustment on test anxiety. One of the reasons for this finding in this present research is that secondary school students may not have mastered their school environment and may feel overwhelmed by school activities that they get anxious during test. This is at variance with Alam \& Halder (2018) who found a statistical significant negative correlation between test anxiety and adjustment. One possible rational for this variance is that this present study looked at adjustment as it relates to school and it also looked at anxiety of secondary school students while the study of Alam \& Halder (2018) looked at adjustment in general.

The finding of the present study shows also that locus of control does not significantly predicts statistics anxiety from table 1:4 and 1:5 where $\mathrm{P}>$ .05 when data was analyzed using simple regression. Coefficient of determination shows that only $1 \%$ of the variation in the proportion of locus of control can be accounted for by the prediction of school adjustment on test anxiety. This prediction can be as a result of students viewing test as a task that is difficult.This is almost in line with the findings of Ravin (2008) who found out that both general locus of control and academic locus of control are mediators of the relationship between socially-prescribed perfectionism and test anxiety. Though general locus of control predicted test anxiety (at a small percentage) this prediction statistically was not significant, the point of divergence between these two studies is that locus of control as a variable was studied to see its mediation on socially prescribed perfectionism and test anxiety for undergraduates students by Ravins (2008) while this study examined general locus of control prediction on test anxiety. Another reason for this differences in findings may not be unconnected with differences in cultural or ethnic background as this study was conducted in a typical Nigerian secondary setting while that of Ravin (2008) was conducted in a typical American University.

Another outcome from this present study was that there is a positive relationship between achievement motivation and test anxiety and that achievement motivation significantly predicts test anxiety. As can be seen from table 1:6 and 1:7 where $\mathrm{P}>.05$ when data was analyzed using simple regression. Coefficient of determination shows that only $3 \%$ of the variation in the proportion of achievement motivation can be accounted for by the prediction of achievement motivation on test anxiety. The reason for this can be that when student have achievement motivation trait, then they may in the process of striving for excellence may 
experience conflict between trying to avoid failure and succeeding. This finding in some way is in disagreement with Khan, Haider, Ahmed, and Khan (2011) who in a study, reported a negative relationship between achievement motivation and anxiety and. Similarly, in 2015, Khalaila found that nursing students with high intrinsic motivation experienced low level of test anxiety. While Balogun et al (2017) study showed that achievement motivation significantly moderated the relationship between test anxiety and academic performance, a study by Chuanan (2016) found out that there is no significant correlation between the academic anxiety and achievement motivation of students. Though somewhat similar these studies a major point of difference is that this study examined the percentage of prediction of achievement motivation on test anxiety while studies reviewed showed if a relationship exist between the variables. Also, difference in findings could be accounted for by difference in population and culture.

Table 1.8 and 1.9 revealed that school adjustment, locus of control and achievement motivation jointly significantly predicts test anxiety test anxiety. As can be seen from table 1:8 and 1:9 where $\mathrm{P}>.05$ when data was analyzed using multiple regression. Coefficient of determination shows that $9 \%$ of the variation in the proportion of test anxiety can be accounted for by the joint prediction of school adjustment, locus of control and achievement motivation as $\mathrm{F}(3,387)=13.041 \mathrm{P}<$ 05. A reason for this finding is that when students are not well adjusted to a school, and they tend not to feel relax and freely take test and if this is coupled with them seeing testing as a difficult task as well as them experiencing conflict between trying to avoid failure and succeeding they may experience high level of test anxiety. Close research carried out by Onukwofor \& Ugwu (2017) found that selfconcept, test anxiety and achievement motivation jointly significantly predict academic achievement. Though similar, the point of divergent is that while most variables of the variables in the study studies are similar, the positioning of the variables as independent or dependent variable in the study differs

In conclusion test anxiety of secondary school students was seen to be high, school adjustment and achievement motivation was seen to predict test anxiety significantly with locus of control predicting test anxiety but not significantly. Jointly, school adjustment, locus of control and achievement motivation predicted test anxiety significantly.
It is therefore recommended that secondary school management should have guidance counselors who are professionally trained to help in handling students with test anxiety in junior secondary school, as this disorder if not properly treated will hinder the students' academic progression. Counsellors should also counsel students on their motivation for achievement, locus of control and adjustment to school so they will be balanced in these arears. Stakeholders (school management and administrators, teachers, counselor and parents) should not present test and students performance in it to students in such a way that students feel that they are not good enough if they do not do well in test. Also, test developers when developing test should ensure that test possesses good psychometric properties which can take away any anxiety that test takers might experience due to a test possessing low psychometric properties.

\section{References.}

[1] Alam, K. \& Halder K.U. Test anxiety and adjustment

[2] Among secondary school students. International Journal of Research andAnalytical Review. Vol 5(3) 675-683

[3] Balogun, A G., Balogun,, S.K. \& Onyencho, C.V

[4] (2017). Test anxiety and academic performance among undergraduates: The moderating role of achievement motivation. The Spanish Journal of Psychology 20 e14 1-8. doi:10.1017/sjp.2017.5

[5] Bernstein, D. A., Penner, L.A. ClerkeStewart, A, \&

[6] Roy, E. J. (2006). Psychology (7th ed) Boston: Houghton Mifflin.

[7] Cassady J. C. (2010). Test anxiety: Contemporary

[8] theories and implications for learning. In J. C. Cassady (Ed.), Anxiety in school: The causes, consequences, and solutions for academic anxieties (pp. 7-26). New York, NY: Peter Lang

[9] Chauhan A. (2016). An Achievement Motivation and

[10] Academic Anxiety of School Going Students. Psychology and Behavioral Science International Journal; 1(4): 555566.

DOI:10.19080/PBSIJ.2016.01.555567002 
[11] Erdoğan A., Kesici S., \& Sahin I. (2011). Prediction

[12] of high school students' mathematics anxiety by their achievement motivation and social comparison. Elementary Education Online, 10, 646-652.

[13] Ergene T. (2011). The relationship among test

[14] anxiety, study habit, achievement motivation, and academic performance among Turkey high school students. Education and Science, 36, 320-330.

[15] Khan Z., Haider Z., Ahmed N., \& Khan S. (2011).

[16] Sports achievement motivation and sports competition anxiety: A relationship study. Journal of Education and Practice, 2, 1-5.

[17] McDonald A. S. (2001). The prevalence and effects

[18] of test anxiety in school children. Educational Psychology, 21, 89-101. https://doi.org/10.1080/01443410020019867

[19] Khalaila R. (2015). The relationship between [20] academic self-concept, intrinsic motivation, test anxiety, and academic achievement among nursing students: Mediating and mediating effects. Nurse Education Today, 35 , 432-438. https://doi.org/10.1016/j.nedt.2014.11.001

[21] Lakhani P. K, Jain K., \& Chandel P.K (2017) School

[22] Adjustment, Motivation and Academic Achievement among Students. International Journal of Research in Social Sciences. Vol.7 (10) 333- 348

[23] Mondal P., Ghosh A., \& Das S. S. (2013).

[24] Relationship between anxiety and achievement motivation of chess players. Physical Education, 3, 443-444.

[25] Onukwufor J. N \& Ugwu C. J.(2017). Self[26] Concept, Test Anxiety and Achievement Motivation Aspredictors Of Academic Achievement In Physics Among Secondary School Students In Rivers State, Nigeria. Journal of Education and Practice. Vol.8, No.33,

[27] Onyeizugbo E. U. (2010). Self-efficacy and test

[28] Anxiety as correlates of academic performance. Educational Research, 1, 477480.

[29] Onyekuru B.U. \& Ibegbunam, J.O.( 2014).

[30] Relationships among Test Anxiety, Locus of Control and Academic Achievement among
College Students. European Scientific Journal vol.10, (13) 384-401387

[31] Putwain D. W., Woods K. A., \& Symes W. (2010).

[32] Personal and situational predictors of test anxiety of students in post-compulsory education. British Journal of Educational Psychology, 80, 137-160. https://doi.org/10.1348/ 000709909X466082

[33] Ravin, S.K. 2008 The mediating effect of locus of

[34] Control in the relationship between sociallyprescribed perfectionism and test anxiety Unpublished Doctoral dissertation

[35] Rezazadah, M, \& Tavakoli, M. (2009). Investigating

[36] the relationship among test anxiety, gender academic achievement and years of study: A case of Iranian EFL University students. English Language Teaching. 2 (4) 68-74

[37] Zeidner, M. (1998) Test Anxiety. The state of art. New York plenum. 